\title{
The effect of different salinity levels in okra fruit by split- plot design
}

\author{
M. Parveen ${ }^{1}{ }^{*}$, S. Saima ${ }^{2}$, M. I. Ullah ${ }^{3}$ \\ ${ }^{1}$ Department of Statistics, Bahauddin Zakariya University, Multan, Pakistan \\ ${ }^{2}$ Institute of Pure and Applied Biology, Bahauddin Zakariya University, Multan, Pakistan \\ ${ }^{3}$ Department of Statistics, Virtual University of Pakistan, LRO Lahore, Pakistan
}

\author{
Keywords \\ Block design \\ Split-plot design \\ Fractional factorial experiment \\ ANOVA \\ Multiple comparison test
}

Received: 12 March 2020

Accepted: 07 May 2020

Published: 12 Aug 2020

\begin{abstract}
In this study, we used the fixed-effect model to identify the best Abelmoschus esculentus (okra) production in Multan by applying a split-plot design. The main purpose of the study was to discuss the different factors which are affecting Okra production. The data were collected from the Department of Botany of Bahauddin Zakariya University, Multan. Descriptive and inferential statistics are applied to achieve the goals of the study. For the descriptive study, made a histogram and inferential statistics (testing of hypothesis) about the quantitative data was used the ANOVA technique. After identifying the significant factors, DMR test apply. The goal of the study is to establish an appropriate model for the data to achieve better production. For data analysis, we use MS Excel, Statistix 10, and Minitab.
\end{abstract}

(C) 2020 The Author(s). Published by TAF Publishing.

\section{INTRODUCTION}

The efficient use of the experimental design method is an important requirement for fast and reliable progress in many branches of today's society. Field researchers always need to reach the right biological decisions relying on a strong and statistical basis, which results in high precision. Yet, they usually encounter problems associated with soil heterogeneity that are most often difficult to detect a priori. Locally, according to 'field management' and 'watering schematic patterns', problems associated with soil fertility gradients are expected to be higher. These problems are often difficult to account for by laying out experimental designs that are unable to handle such heterogeneity, especially if it is complex or because of many aggregated factors. Depending on the experimental trial, there are many statistical techniques researchers could choose to achieve their goal. The Randomized Complete Block Design (RCBD) is one of the most widely used experimental designs.
Experimental design involves not only the selection of suitable independent, dependent, and control variables but planning the delivery of the experiment under statistically optimal conditions given the constraints of resources. Split plots are another class of experimental designs for factorial treatment structures. A Split-Plot Design (SPD) is chosen when some factors applying in a large area and some in small units. The terminology of SPD comes from agricultural experimentation. Since split-plot design is a special case of a factorial treatment structure and it is used when some factors are harder (or more expensive) to vary than others. Basically, SPD comprises of two experiments with different experimental units of different "sizes," e.g., in agronomic field trials, certain factors require "large" experimental units, whereas other factors can be easily applied to "smaller" plots of land.

There are two major advantages of SPD. First, estimates of subplot treatments and their interaction with whole plot

\footnotetext{
${ }^{*}$ Corresponding author: Maqsooda Parveen

†email: maqsooda.parveen@bzu.edu.pk
} 
treatments are obtained in SPD than in RCBD. Second, two or more factors needing relatively large and small units can be combined in the same experiment of SPD. SPDs have recently received much attention in the literature (see, for example, $[1,2,3,4,5,6])$.

\section{MATERIAL AND METHODS}

[7] introduced split-plot designs when studying the effectiveness of irrigation and fertilizer on agricultural yields. He assigned the studied irrigation methods to entire plots of land while assigning the different fertilizers to subplots of the field that received the same irrigation treatment. [8] compared the effectiveness of SPD over RCBD. The Relative Efficiency (RE) statistic values were compared. [9] used a split-split plot experimental design to study the crafting of an apposite experimental design. This can facilitate the simultaneous study of the individual and conjunctive effects of several experimental designs treatments. [10] investigate the effects of process parameters in the production of polypropylene-grass composite using split-split plot experimental designs. [11] addressed the issues when designing the experiment and when analyzing the data for non-replicated cases. The overview and discuss some of the most important methods for analyzing split-plot data. The focus is on estimation, testing, and model validation.

[12] performed the field experiment to compare the impact of different organic manures and NPK fertilizer on soil properties, growth, yield, proximate and mineral contents of okra. The authors used the ANOVA and DMRT and concluded that okra with poultry manure under moderate rainfall enhances the health benefit from the fruit; however, quality reduces except its mucilage content. [13] carried out a one-time split-plot design with three iterations for each treatment for the experiment that included 8 treatments. The results showed the significant impact of seed soaking before planting in the overall productivity of the plant. Similarly, they found that the addition of organic and mineral fertilizers together to be significant.

[14] finding optimum covariate designs for estimation of covariate parameters in standard split-plot and strip-plot design set-ups with the levels of the whole-plot factor in $r$ randomized blocks. [15] reviewed SPDs for full and fractional factorial experiments and explained why they often arise in industrial experiments. [16] investigated the goodness of four different organic fertilizers on crop (maize) yield and used SPD and two-way ANOVA with interaction models to carry out the analysis and apply the LSD test. [17] presented a method based on the Kronecker prod- uct representation of orthogonal designs that were used for constructing two-level split-plot and multistage experiments. [18] reviewed recent developments and provided guidelines for the use of split-plot designs in industrial applications.

Many researchers study the growth, yield, and quality of Okra by comparing the impact of different plant densities, nitrogen level, soil, irrigation water salinity, irrigation intervals, salicylic acid, gibberellic acid, and organic manures, etc. Few references are [19, 20, 21, 22, 23].

Most of the existing research about yield and/or growth okra makes use of some basic statistics, graphical representations, One-way, Two-way, or repeated ANOVA with some multiple comparison tests. Therefore, most of the existing studies lack the use of some better statistical methodology, such as split-plot design. In this, we make use of models such as SPD for the identification of the best okra production. The assumption of ANOVA, SPD model, and statistical analysis are described below. First, we check three assumptions of ANOVA. Normality assumption, the plot of residuals in time sequence (for independence assumptions), the plot of residuals versus fitted values, and Bartlett's test (for homogeneity of variances).

\section{A. Bartlett's Test for Equality of Variance}

The residual plots are frequently used to diagnose inequality of variance; several statistical tests have also been proposed. These tests may be viewed as formal tests of the hypothesis,

$H_{0}: \sigma_{1}^{2}=\sigma_{2}^{2}=\cdots=\sigma_{a}^{2}$

$H_{1}$ : above not true or at least one $\sigma_{i}^{2}$

A widely used procedure is Bartlett's test. The procedure involves computing a statistic whose sampling distribution is closely approximated by the chi-square distribution with a-1 degrees of freedom when the random samples are from independent normal populations. The test statistic is

$\chi_{0}^{2}=2.3026 \frac{q}{c}$

where

$q=(N-a) \log _{10} S_{p}^{2}-\sum_{i=1}^{a}\left(n_{i}-1\right) \log _{10} S_{i}^{2}$

$c=1+\frac{1}{3(a-1)}\left(\sum_{i=1}^{a}\left(n_{i}-1\right)^{-1}-(N-a)^{-1}\right)$

$S_{p}^{2}=\frac{\sum_{i=1}^{a}\left(n_{i}-1\right) S_{i}^{2}}{N-a}$

and $S_{i}^{2}$ is the sample variance of the $i$ th population. The quantity $q$ is large when the sample variances $S_{i}^{2}$ differ greatly and are equal to zero when all $S_{i}^{2}$ are equal. Therefore, we should reject $H_{0}$ on values of $\chi_{0}^{2}$ that are too large; that is, we reject $H_{0}$ only when,

$\chi_{0}^{2}>\chi_{\alpha, a-1}^{2}$ 
where $\chi_{\alpha, a-1}^{2}$ is the upper $\alpha$ percentage point of the chisquare distribution with $a-1$ degrees of freedom. Secondly, the split-plot design model was adopted for this work, and ANOVA results were produced. In arriving at the results, SPSS, MINITAB, and EXCEL-SOLVER computer software were used to analyze the data.

1) The design of split-plot experiments: The linear model for the split-plot design is,

$y_{i j k}=\mu+\tau_{i}+\beta_{j}+(\tau \beta)_{i j}+\gamma_{k}+(\tau \gamma)_{i k}+(\beta \gamma)_{j k}+(\tau \beta \gamma)_{i k}+\epsilon_{i j k}\left\{\begin{array}{c}i=1,2, \ldots, r \\ j=1,2, \ldots, a \\ k=1,2, \ldots, b\end{array}\right\}$

- $y_{i j k}$ is the response of $k^{\text {th }}$ replicate of the $i^{\text {th }}$ level of factor $\tau$ and the $J^{\text {th }}$ level of factor $\beta$.

- $\mu$ is the overall mean.

- $\gamma_{k}$ is the random effect of the $k^{t h}$ replicate with $\gamma_{k} \sim$ $N\left(0, \sigma^{2}\right)$.
- $\beta_{j}$ is the fixed effect of the level of the $j^{\text {th }}$ level factor $\beta$. Parameters are estimated by the least square estimation method.

TABLE 1

ANOVA FOR SPLIT PLOT DESIGN

\begin{tabular}{lllll}
\hline \hline Source & SS & df & MS & F-Ratio \\
\hline Block Row $\left(R_{i}\right)$ & $S S_{R}$ & $(r-1)$ & $\frac{S S_{R}}{(r-1)}$ & $\frac{S S_{R}}{(r-1)} / M S_{w R}$ \\
Whole-Plot $\left(W_{j}\right)$ & $S S_{W}$ & $(\tau-1)$ & $\frac{S S_{W}}{(\tau-1)}$ & $\frac{S S_{W}}{(\tau-1)} / M S_{w R}$ \\
Whole-Plot Error $\left(W R_{i} j\right)$ & $S S_{w R}$ & $(\tau-1)(r-1)$ & $\frac{S S_{w R}}{(\tau-1)(r-1)}$ & $\frac{S S_{B}}{(s-1)} / M S_{B}$ \\
Sub-Plot $\left(B_{k}\right)$ & $S S_{B}$ & $(s-1)$ & $\frac{S S_{B}}{(s-1)}$ & $\frac{S S_{W B}}{(\tau-1)(s-1)} / M S_{B}$ \\
$(W-P(S-P))_{W B}$ & $S S_{W B}$ & $(\tau-1)(s-1)$ & $\frac{S S_{W B}}{(\tau-1)(s-1)}$ & \\
S-P Error & $S S_{B}$ & $\tau r s-1$ & & \\
Total & $S S_{T}$ & & & \\
\hline \hline
\end{tabular}

Once an ANOVA test has been completed, the researcher may still need to understand subgroup differences among the different experimental and control groups. The subgroup differences are called "pair-wise" differences. ANOVA does not provide tests for pair-wise differences. When the researcher needs to test pair-wise differences, follow-up tests called post-hoc tests are required, such as Duncan's multiple range tests. Duncan's multiple range tests make use of the studentized range distribution to determine critical values for comparisons between means.

\section{ANALYSIS, RESULTS AND DISCUSSION}

An experimenter was interested in comparing three salinity levels ${ }^{1}$ and two types of Abelmoschus esculentus (Okra) 2. As the main interest was in the Abelmoschus esculentus, so the experiment was performed in randomized complete block design with seven blocks keeping salinity levels in main plots and Abelmoschus esculentus in sub-plots, performed a split-plot design.
The data about the response factor is the dry weight of Leaves, dry weight of root, and length of shoot obtained from the Department of Botany, Bahauddin Zakariya University Multan.

\section{A. Data set: Dry weight of leaves}

To study the influence of $\mathrm{NaCl}$ stress on various biochemical components in Okra (Abelmoschus esculentus) fruit, two differential cultivars, 'Nirali' and 'Posa Sawni', were grown under non-saline and saline conditions until fruit development. The response factor is the dry weight of Leaves.

\footnotetext{
Salinity is the saltiness or amount of salt dissolved in a body of water, called saline water.

2 Abelmoschus esculentus(Okra) is an important vegetable crop.
} 


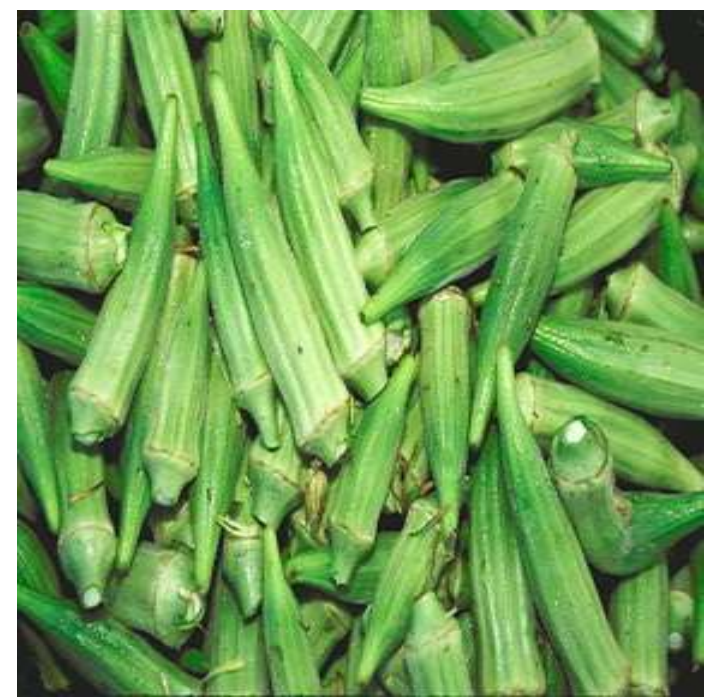

Fig. 1. Okra

TABLE 2

DRY WEIGHT OF LEAVES

\begin{tabular}{|c|c|c|c|c|c|c|}
\hline \multirow[t]{4}{*}{ Replication } & \multicolumn{6}{|c|}{ Salinity* } \\
\hline & \multicolumn{2}{|c|}{ Control } & \multicolumn{2}{|c|}{$25 \% \mathrm{Nacl}$} & \multicolumn{2}{|c|}{$50 \% \mathrm{Nacl}$} \\
\hline & \multicolumn{2}{|c|}{ Abelmoschus esculentus } & \multicolumn{2}{|c|}{ Abelmoschus esculentus } & \multicolumn{2}{|c|}{ Abelmoschus esculentus } \\
\hline & Rama posa & Nerali & Rama posa & Nerali & Rama posa & Nerali \\
\hline 1 & 0.323 & 0.54 & 0.263 & 0.396 & 0.136 & 0.345 \\
\hline 2 & 0.396 & 0.546 & 0.263 & 0.403 & 0.133 & 0.375 \\
\hline 3 & 0.473 & 0.593 & 0.216 & 0.486 & 0.15 & 0.32 \\
\hline 4 & 0.49 & 0.643 & 0.36 & 0.53 & 0.143 & 0.313 \\
\hline 5 & 0.47 & 0.605 & 0.363 & 0.503 & 0.146 & 0.366 \\
\hline 6 & 0.436 & 0.673 & 0.326 & 0.456 & 0.176 & 0.355 \\
\hline 7 & 0.473 & 0.526 & 0.33 & 0.425 & 0.203 & 0.263 \\
\hline
\end{tabular}

The data about Salinity has three levels: Control, $25 \% \mathrm{NaCl}$, $50 \% \mathrm{NaCl}$

- Control: about 10 to 20 percent, the drainage or leaching fraction

- $25 \% \mathrm{NaCl}$ : A 25\% NaCl solution has twenty-five grams of sodium chloride dissolved in $100 \mathrm{ml}$ of solution.

- $50 \% \mathrm{NaCl}: \mathrm{A} 50 \% \mathrm{NaCl}$ solution has fifty grams of sodium chloride dissolved in $100 \mathrm{ml}$ of solution.

Abelmoschus esculentus has two varieties; Rama posa and Nerali

\section{B. Assumptions of ANOVA}

Testing the Underlying Assumptions: Each of the samples was independently sampled, and each of the groups has the same sample size.

ISSN: $2414-3103$

DOI: http://doi.org/10.20474/japs-6.1.2
1) Normality test: $H_{0}$ : The population is normally distributed $H_{1}$ : The population is not normally distributed.

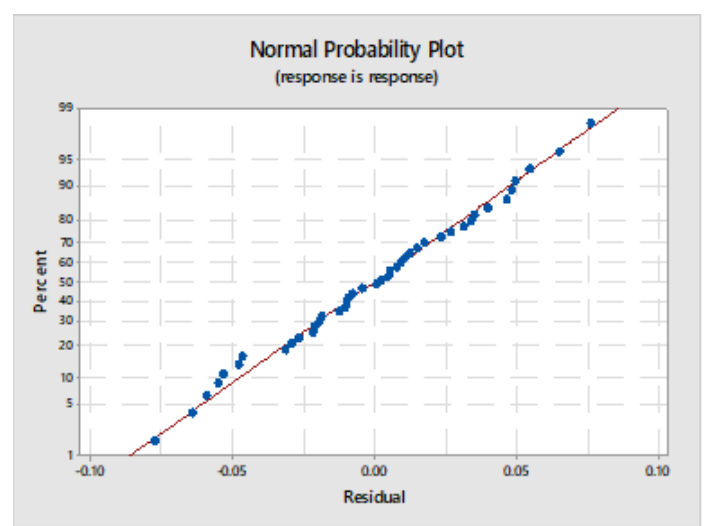

Fig. 2. Normal probability plot 


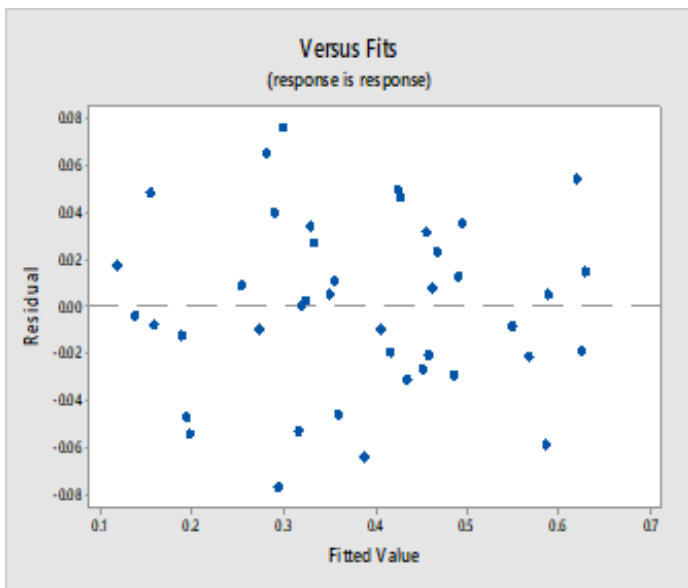

Fig. 3. Plot of residuals versus fitted values shows that the assumption of homogeneity of variances is satisfied.

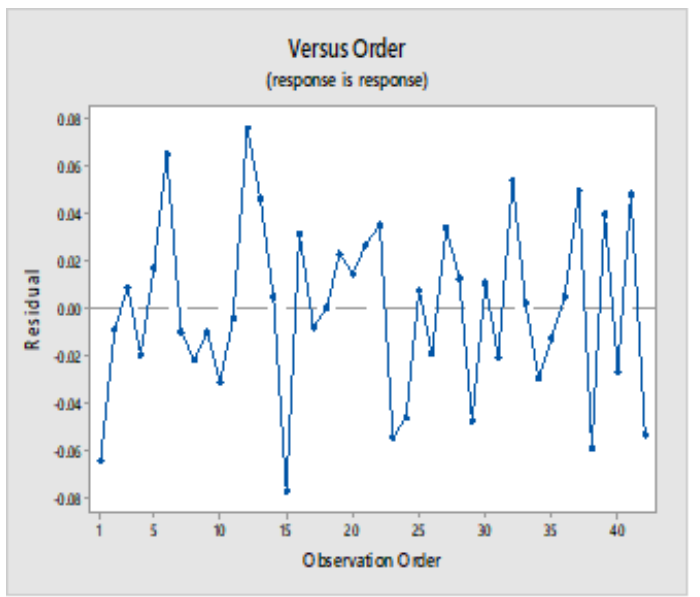

Fig. 4. Plot of residuals versus run order shows no correlation between the residuals. A tendency to have runs of positive and negative residuals indicates no correlation.

2) Equality of variance test: $H_{0}$ : The variances are equal. $H_{1}$ : The variances are not equal.

The computed $\chi_{o}^{2}=4.805$ of Bartlet's test is less than the tabulated value of $\chi_{0.05,5}^{2}=11.07$, so we accept the null hypothesis and conclude that all six variances are homoge- neous.

3) Split plot design: The results from the split-plot design is given below

TABLE 3

ANALYSIS OF VARIANCE

\begin{tabular}{llllll}
\hline \hline Source & DF & Adj SS & Adj MS & $F$-Value & $p$-Value \\
\hline Replication & 6 & 0.033094 & 0.005516 & 3.20 & 0.026 \\
Salinity & 2 & 0.505730 & 0.252865 & 146.72 & $0.000^{*}$ \\
Error1(Rep*salinity) & 12 & 0.023122 & 0.001927 & 1.12 & 0.403 \\
Abelmoschus esculentus(variety) & 1 & 0.274106 & 0.274106 & 159.05 & $0.000^{*}$ \\
salinity *Abelmoschus esculentus & 2 & 0.001523 & 0.000762 & 0.44 & 0.650 \\
Error2 & 18 & 0.031020 & 0.001720 & & \\
Total & 41 & 0.868600 & & & \\
\hline \hline
\end{tabular}

${ }^{*} \mathrm{P}<0.05$ 
The $p$-value for interaction is statistically non-significant, showing that salinity and varieties are independent. The main effects make meaning and are significant for both salinity and varieties.
4) Duncan's multiple range test: The comparison of salinity and varieties using Duncan's multiple range test are salinity means.

TABLE 4

ANALYSIS OF VARIANCE

\begin{tabular}{lll}
\hline \hline $\mathrm{p}$ & Difference & LSR \\
\hline 2 & $\bar{s}_{1}-\bar{s}_{2}$ & $0.513-0.380=0.133<0.036$ \\
3 & $\bar{s}_{1}-\bar{s}_{3}$ & $0.513-0.244=0.269<0.370$ \\
2 & $\bar{s}_{2}-\bar{s}_{3}$ & $0.380-0.244=0.136>0.036$ \\
\hline \hline
\end{tabular}

The result shows that $\mathrm{S} 1$ (Control) and S3: $(50 \% \mathrm{NaCl})$ give the same, but S1 (Control) and S2 $(25 \% \mathrm{NaCl}), \mathrm{S} 2(25 \%$ $\mathrm{NaCl})$, and $\mathrm{S} 3(50 \% \mathrm{NaCl})$ gives different dry weight of leaves and this finding confirms the results by Unlukara et al. 2008.

\section{CONCLUSION}

The present study gives the application of the Design of Experiment that will be helpful for better understand the agricultural growth and development of Crops. The data on the dry weight of Okra leaves (agricultural crop) was collected in an experimental study conducting by the Department of Botany, Bahauddin Zakariya University, Multan, Pakistan. The experiment and data collected fulfill all the assumptions of ANOVA using normality plot and Bartlet's test. We applied the split-plot design to check the effect of salinity and abelmoschus esculentus (variety) through the response of dry weight of leaves. The null hypotheses of salinity and abelmoschus esculentus (variety) were rejected. The DMR test was applied to identify which pair contributes significantly, and it was found that dry weight of leaves that salinity $1\left(s_{1}\right)$ and salinity3 $\left(S_{3}\right)$ gives the same but salinity1 $\left(S_{1}\right)$ and salinity2 $\left(S_{2}\right)$, salinity2 $\left(S_{2}\right)$ and salinity3 $\left(S_{3}\right)$ gives a different response. Therefore, it can be concluded that all treatments of salinity stress had adverse effects on okra plants in terms of growth and some key physiological at- tributes. In all growth parameters, Rama posa had shown less growth and was more affected by salinity stress levels, but Nerli was less affected by salt stress and showed better performance under the salt stress treatments as compared to Rama posa. So it can be stated that Nerali was salt tolerant while Rama posa was salt sensitive.

\section{STUDY IMPLICATIONS}

Instead of avoiding the SPD due to computational complexities as viewed by some experimenters and scholars, a professional should be contacted it will go a long way in reducing biased results in estimating factors significant contribution to the experimental response.

\section{LIMITATIONS}

The split-plot design analysis becomes more complex when data are missing. Implementing the design can be difficult and requires advanced knowledge of a specific discipline.

\section{FUTURE RESEARCH RECOMMENDATIONS}

The authors believe that the results proposed could be useful, helpful, and insightful to a farmer in understanding the dynamics of the interplay of factors.

\section{REFERENCES}

[1] D. Bingham and R. Sitter, "Design issues in fractional factorial split-plot experiments," Journal of Quality Technology, vol. 33, no. 1, pp. 2-15, 2001. doi: https://doi.org/10.1080/00224065.2001.11980043

[2] S. Bisgaard, "The design and analysis of $2 \mathrm{k}-\mathrm{p} \times 2$ q-r split plot experiments," Journal of Quality Technology, vol. 32, no. 1, pp. 39-56, 2000. doi: https://doi.org/10.1080/00224065.2000.11979970

[3] G. Box and S. Jones, "Split-plot designs for robust product experimentation," Journal of Applied Statistics, vol. 19, no. 1, pp. 3-26, 1992. doi: https://doi.org/10.1080/02664769200000001 
[4] S. M. Kowalski, J. A. Cornell, and G. G. Vining, "Split-plot designs and estimation methods for mixture experiments with process variables," Technometrics, vol.44, no. 1, pp. 72-79, 2002. doi: https://doi.org/10.1198/004017002753398344

[5] J. D. Letsinger, R. H. Myers, and M. Lentner, "Response surface methods for bi-randomization structures," Journal of Quality Technology, vol. 28, no. 4, pp. 381-397, 1996. doi: https://doi.org/10.1017/s0020268100030833

[6] D. C. Montgomery, Design and Analysis of Experiments, 8th ed. Hoboken, NJ: John Wiley \& Sons, 2017.

[7] R. Fisher, "Statistical methods for research workers," Guildford, UK: Genesis Publishing, Survey, 1925.

[8] I. David and M. Adehi, "Effectiveness of split-plot design over randomized completeblock design in some experiments," Journal of Biology, Agriculture and Healthcare, vol. 4, no. 19, pp. 75-80, 2014.

[9] S. Omotehinse and A. Igboanugo, "Statistical study of factors influencing surface roughness of machined work-piece using split-split plot design," Scanning, vol. 1, no. 1, pp. 13-28, 2019.

[10] D. Olodu and J. Osarenmwinda, "Investigation of polypropylene-grass composite using split-split plot experimental design," Advances in Engineering Design Technology, vol. 1, no. 1, pp. 40-48, 2019. doi: https://dx.doi.org/10.37933/ nipes/2.3.2020.22.

[11] T. Næs, A. H. Aastveit, and N. Sahni, “Analysis of split-plot designs: An overview and comparison of methods," Quality and Reliability Engineering International, vol. 23, no. 7, pp. 801-820, 2007. doi: urlhttps://doi.org/10.1002/qre.841

[12] A. O. Adekiya, W. S. Ejue, A. Olayanju, O. Dunsin, C. M. Aboyeji, C. Aremu, K. Adegbite, and O. Akinpelu, "Different organic manure sources and NPK fertilizer on soil chemical properties, growth, yield and quality of okra," Scientific Reports, vol. 10, no. 1, pp. 1-9, 2020. doi: https://doi.org/10.1101/2020.06.01.127498

[13] H. J. M. Kadim, N. Hamed, "Effect of seed soaking and organic and mineral fertilizers on growth and yield of okra abelmoschus esclentus l. under unheated greenhouses," Plant Cell Biotechnology and Molecular Biology, vol. 22, no. 19, pp. 31-40, 2020.

[14] G. Dutta, P. Das, and N. K. Mandal, "Optimum covariate designs in split-plot and strip-plot design set-ups," Journal of Applied Statistics, vol. 36, no. 8, pp. 893-906, 2009. doi: https://doi.org/10.1080/02664760802520777

[15] J. Ledolter, "Split-plot designs: Discussion and examples," International Journal of Quality Engineering and Technology, vol. 1, no. 4, pp. 441-457, 2010. doi: https://doi.org/10.1504/ijqet.2010.035588

[16] S. Nsikak et al., "On the goodness of four types of organic fertilizers using the Split Plot Design and the two-way block design with interactions," American Journal of Applied Mathematics and Statistics, vol. 5, no. 4, pp. 136-144, 2017. doi: https://doi.org/10.12691/ajams-5-4-4

[17] M. Kulahci and J. Tyssedal, "Split-plot designs for multistage experimentation," Journal of Applied Statistics, vol. 44, no. 3, pp. 493-510, 2017. doi: https://doi.org/10.1080/02664763.2016.1177497

[18] B. Jones and C. J. Nachtsheim, "Split-plot designs: What, why, and how," Journal of quality technology, vol. 41, no. 4, pp. 340-361, 2009. doi: https://dx.doi.org/10.1080/00224065.2009.11917790

[19] M. Alam, K. Hayat, I. Ullah, M. Sajid, M. Ahmad, A. Basit, I. Ahmad, A. Muhammad, S. Akbar, and Z. Hussain, “Improving okra (abelmoschus esculentus l.) growth and yield by mitigating drought through exogenous application of salicylic acid," Fres Environ Bulle, vol. 29, no. 01, pp. 529-535, 2020.

[20] S. Muthucumaran, S. Pathmarajah, and M. Mowjood, "Vertical variation of salinity, electrical conductivity temperature and ph of batticaloa lagoon," International Journal of Applied and Physical Sciences, vol. 1, no. 2, pp. 36-41, 2015. doi: https://doi.org/10.20469/ijaps.50003-2

[21] A. Ünlükara, A. Kurunç, G. D. Kesmez, and E. Yurtseven, "Growth and evapotranspiration of okra (abelmoschus esculentus l.) as influenced by salinity of irrigation water," Journal of Irrigation and Drainage Engineering, vol. 134, no. 2, pp. 160-166, 2008. doi: https://doi.org/10.1061/(asce)0733-9437(2008)134:2(160)

[22] H. Verma, S. Singh, M. Parihar, D. Nawange, and K. Lovewanshi, "Effect of levels of nitrogen and gibberellic acid on growth, yield and quality of okra (abelmoschus esculentus l. moench)," Journal of Pharmacognosy and Phytochemistry, vol. 9, no. 4, pp. 1165-1167, 2020.

[23] F. Yoldaş, S. Ceylan, O. L. Elmacı, I. Duman, E. Duzyaman, and M. Özge, "The effects of different plant densities and nitrogen levels on certain macro and micro element contents of okra," Selcuk Journal of Agriculture and Food Sciences, vol. 32, no. 2, pp. 162-169, 2018. doi: https://doi.org/10.15316/sjafs.2018.80 